\title{
Early Results of the PETTICOAT Technique for the Management of Acute Type A Aortic Dissection
}

\author{
${ }^{1}$ Department of Diagnostic Imaging, Foothills Medical Centre, Calgary, Alberta, Canada \\ ${ }^{2}$ New Brunswick Heart Centre, Saint John Regional Hospital, Saint John, Canada \\ ${ }^{3}$ Mazankowski Alberta Heart Institute, University of Alberta, Edmonton, Alberta, Canada \\ ${ }^{4}$ Department of Cardiac Sciences, Foothills Medical Centre, Calgary, Alberta, Canada
}

Vamshi Krishna Kotha, MD ${ }^{1 *}$, Zlatko I. Pozeg, MD², Eric J. Herget, MD', Michael C. Moon, MD², Jehangir J. Appoo, MDCM ${ }^{4}$ on behalf of the Canadian Thoracic Aortic Collaborative (CTAC)

\begin{abstract}
Conventional surgical techniques for acute Type $A$ aortic dissection (ATAAD) generally fail to address residual dissection in the descending aorta. The persistence of a false lumen is associated with visceral malperfusion in the acute setting and adverse aortic remodeling in the chronic setting. Hybrid aortic arch repair techniques may improve perioperative and long-term mortality by expanding the true lumen and obliterating the false lumen. However, there is a limit to the extent of aortic coverage due to the concomitant risk of spinal cord ischemia. In Type B dissection, the PETTICOAT (Provisional Extension To Induce Complete Attachment) technique, which entails stent graft coverage of the primary intimal tear followed by bare metal stent placement distally, may improve true lumen caliber and promote false lumen thrombosis without increasing the risk of spinal cord ischemia, as intercostal branches remain perfused through the bare metal stents. The technique of hybrid arch with surgical creation of a Dacron landing zone covering a stent graft in the proximal descending aorta and bare metal stents in the thoraco-abdominal aorta is a promising concept in the treatment of ATAAD.

Copyright @ 2017 Science International Corp.
\end{abstract}

\section{Key Words}

Dissection • Stent graft • Endovascular

\section{Introduction}

Despite improvements in surgical techniques for acute Type A aortic dissection (ATAAD), the most recent large registry data published in 2015 suggests a persistently high operative mortality of $15-20 \%[1,2]$. In addition, long-term survival can be compromised by aneurysmal dilatation of the patent residual false lumen in the arch and descending aorta [3]. However, proximal aortic reconstruction (e.g., open hemi-arch anastomoses) generally fails to address persistent dissection in the descending aorta.

To address the issue of early and late mortality, a hybrid approach involving full arch replacement and insertion of an endovascular stent graft into the descending aorta in the setting of ATAAD (Figure 1) has been advocated in patients with distal malperfusion $[4,5]$. The potential benefits of extended arch surgery in patients with ATAAD are 1) resection of primary intimal tears beyond the ascending aorta, 2) exclusion of re-entry tears in the descending aorta, 3) facilitation of re-expansion of the distal true lumen, and 4) promotion of false lumen obliteration. This approach aims to reduce early malperfusion, improve late aortic remodeling, and decrease late mortality without increasing perioperative morbidity and mortality.

* Corresponding Author:

Vamshi Krishna Kotha, MD

Department of Diagnostic Imaging

Foothills Medical Centre

140329 St. NW Calgary, AB T2N 2T9, Canada

Tel.: +1 403944 4634; Fax: +1 403210 9046; E-Mail: vamshikotha@gmail.com 


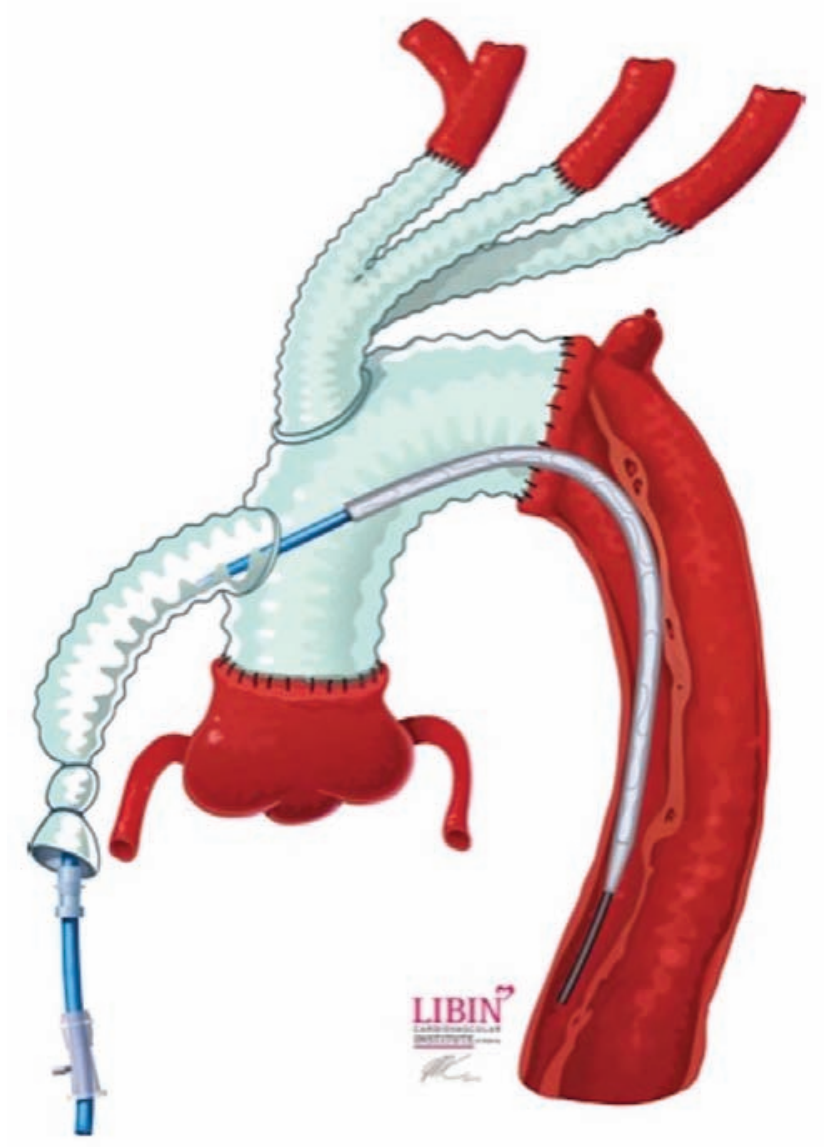

Figure 1. Zone 2 arch technique. The arch is replaced to the level of the left subclavian artery with proximilization of the ostium of the three head vessels. An endovascular stent graft is then deployed across the distal arch and proximal descending aorta (reprinted with permission from www.aorta.ca).

The early mortality rates reported for extended arch procedures demonstrate the safety of such hybrid procedures $[6,7]$.

Some groups have advocated a more aggressive approach to aortic resection in ATAAD with the addition of a frozen elephant trunk [8]. Pochettino et al. hypothesized that most late complications after ATAAD are related to the descending thoracic aorta rather than the arch itself. They advocate placement of an antegrade stent graft into the descending aorta during a standard hemiarch resection [9]. This theoretically serves to stabilize the descending aorta, including true expansion and false lumen thrombosis, which may mitigate the long-term complication of aneurysmal expansion that occurs in up to $80 \%$ of patients [10].
Addressing the dissected descending thoracic aorta early in the setting of ATAAD can have significant benefits and alter the natural history of the disease process $[5,11]$. However, the placement of a covered stent graft, although it expands the true lumen and promotes false lumen thrombosis, is associated with significant risk of spinal cord ischemia [12]. Hence, placement of a distal bare metal stent into the descending thoracic aorta may confer the advantages of a covered stent graft while reducing the risk of spinal cord ischemia. The bare metal stents could be placed just above the origin of the celiac artery but have been safely placed into the infrarenal aorta in our practice.

This technique has been used in Type B dissection, and although the use of bare metal stents was previously described [13], this technique was first reported by Mossop in 2005 to induce distal true lumen expansion while maintaining perfusion to aortic side branches [14] in an effort to beneficially alter the natural history of chronic Type $B$ dissection. The term PETTICOAT (Provisional Extension To Induce Complete Attachment) to describe this technique was first used in the literature by Nienebar in 2006 [15].

In 2012, the Mossop group reported the midterm follow-up of a series of 31 patients ( 13 with ATAAD) treated with this technique. The overall population showed an aorta-related survival of $93 \%$ at 100 months, stable thoracic and abdominal aortic dimensions over a mean follow-up of 57.3 months, and complete false lumen thrombosis in $23 \%$ of cases [16]. This was followed by another report from the same group comparing the shortterm outcomes of this technique compared with treatment by proximal aortic intervention only. This study included 63 patients (40 treated with distal bare metal stenting in addition to proximal intervention and 23 treated with proximal aortic intervention only). They found a significantly higher incidence of early post-operative malperfusion syndrome and an increased number of re-interventions in the latter group over a mean follow-up of 49 months [17].

In 2014, the Mossop group reported a modification of this technique termed STABILISE (Stent-Assisted Balloon-Induced Intimal Disruption and Relamination) used for 11 patients with complicated aortic dissection 
(seven with ATAAD). The overall population showed no aorta-related late adverse events or deaths over a median follow-up of 18 months and complete false lumen obliteration in $90 \%$ of cases [18].

More recently, the STABLE trial, which focused on Type B aortic dissection, showed positive aortic remodeling at 1 year using the PETTICOAT technique $[19,20]$. This trial enrolled 86 patients with aortic dissection treated within 90 days of symptom onset. The 30 -day mortality rate was $4.7 \%$. Of note, $80.3 \%$ of patients exhibited a stable or shrinking transaortic diameter in the thoracic segment (73.9\% at 2 years) and $79.1 \%$ in the abdominal segment (66.7\% at 2 years).

In comparison, most patients who undergo surgical repair of ATAAD are left with a residual dissection involving the descending aorta, often extending into the abdomen. With the encouraging early results of the STABLE trial, it may be appropriate to utilize the PETTICOAT technique in ATAAD patients undergoing hybrid arch surgery consisting of arch replacement and a short endograft in the proximal descending aorta. In the acute setting, longer covered endografts are generally avoided due to the risk of spinal cord ischemia. The use of distal bare metal stents would minimize the risk of spinal cord ischemia while potentially helping expand the true lumen distally and facilitating beneficial distal aortic remodeling.

\section{Advantages and Disadvantages}

The Cook Zenith Dissection device (Cook Medical, Bloomington, IN) is currently the only commercially available bare metal stent for such application. It comes in large sizes ( 36 and $46 \mathrm{~mm}$ ) to accommodate large aortic diameters and has minimal radial force and large interstices. The large interstices allow for perfusion of side branches, thus avoiding the risk of spinal cord ischemia. Due to the low radial force, these grafts are less inclined to cause a stent-induced new entry tear [21, 22]. The large interstices also permit direct stenting of the renal or other visceral arteries if necessary, especially when they originate from the false lumen. In fact, true lumen expansion by the stents should facilitate branch vessel stenting across the false lumen in cases of static obstruction.

Overall, rapid true lumen expansion utilizing this technique may prevent malperfusion in ATAAD and promote positive aortic remodeling, with early false lumen obliteration during follow-up without any significant increase in the risk of spinal cord ischemia. The window during which one would be able to reexpand the true lumen is unknown and thus needs to be investigated.

There is a small increment in fluoroscopy time and cost with this technique, but considering the virulent nature of ATAAD and the existing costs of treating these patients, we do not feel that these are major disadvantages of using bare metal stents.

Due to the low radial force and relative lack of columnar support, there is a risk of stent misalignment when these devices are used, which has been reported in 4 out of 25 patients by one group [23]. Delayed aortic rupture could still occur with this technique due to continued perfusion of the false lumen [19], but we believe that this risk can be lowered by promoting positive aortic remodeling. Finally, complications of stent graft usage including device migration [24] and retrograde dissection [19] have been reported, although the latter would not be of major concern following ATAAD repair. Figure 2 shows an example of hybrid arch repair with bare metal stents distally.

\section{Future Steps}

The PETTICOAT technique has not been sufficiently studied systematically in ATAAD. Theoretically, distal aortic remodeling may be further improved in patients who are already undergoing a hybrid arch operation to exclude the primary entry tear and obliterate the false lumen proximally. We are currently starting a multi-center randomized clinical trial of hybrid arch versus hybrid arch with bare metal stents distally in the setting of ATAAD. Clinical and radiologic outcomes under study include time to complete false lumen thrombosis, rate of aortic growth, incidence of aortic rupture and visceral malperfusion, and technical success rate.

\section{Conclusion}

Management of the entire aorta in the setting of ATAAD to achieve complete elimination/thrombosis of the false lumen is challenging. The STABLE trial shows 


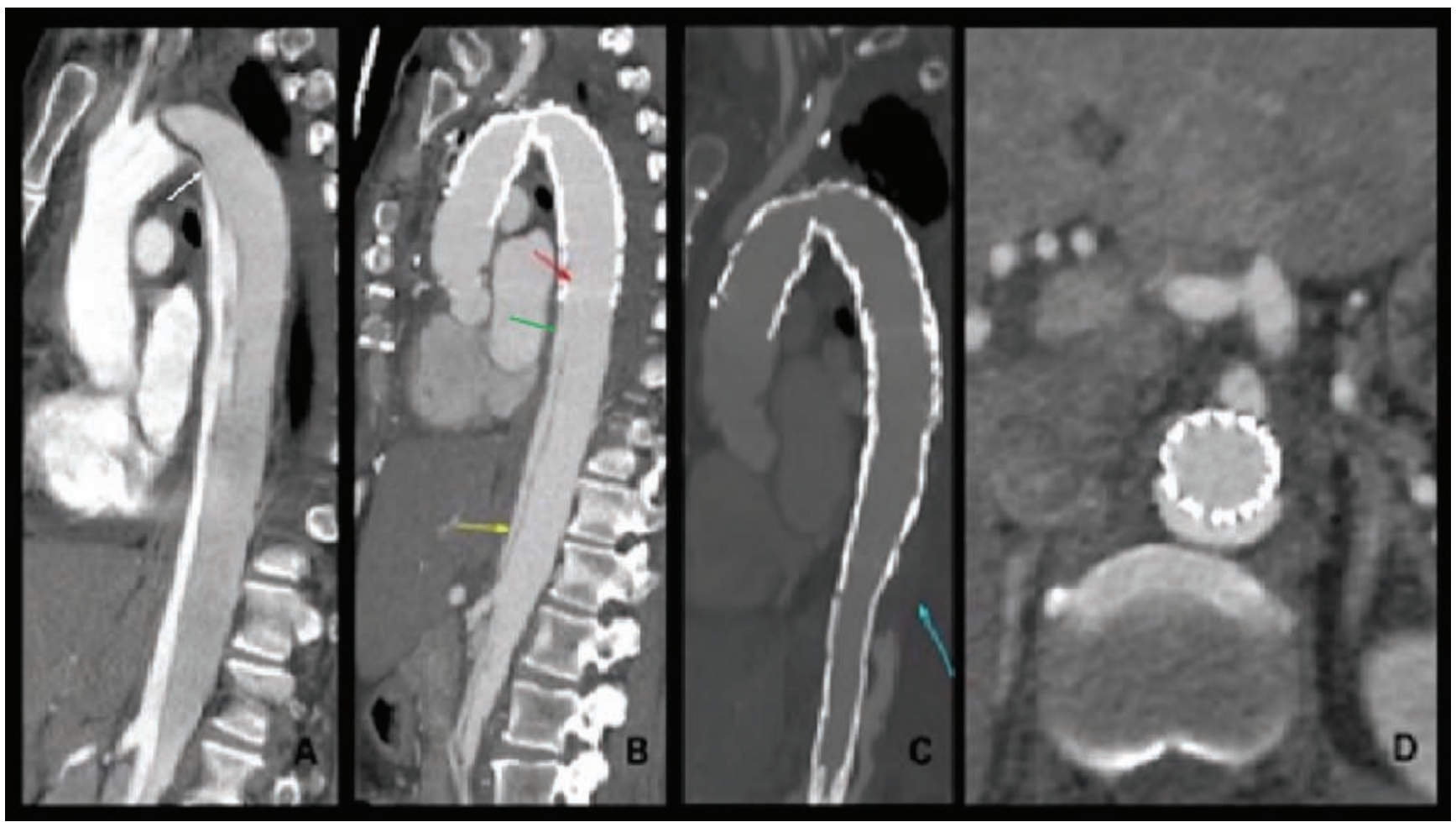

Figure 2. Case of a 48-year-old woman with ATAAD treated with a hybrid arch and staged bare metal stent. (Panel A) Computed tomography $(C T)$ image demonstrating primary intimal tear distal to the left subclavian origin (white arrow). Note the thrombosed false lumen in the ascending aorta and the severely effaced true lumen in the descending aorta. The distal arch was aneurysmal at $4.8 \mathrm{~cm}$. (Panel B) CT image 1 week post-hybrid arch demonstrates intimal rupture and a large tear (green arrow) at the distal landing zone of the endovascular device in the mid-thoracic descending aorta (red arrow). The true lumen was severely narrowed at the level of the celiac trunk and superior mesenteric artery (yellow arrow). (Panel C) CT image after second operation consisting of coverage of large new entry tear with a short covered graft, with a $46 \times 164-\mathrm{mm}$ Cook Dissection bare metal stent deployed from the mid-thoracic aorta to the abdominal aorta, landing just below the renal arterial origin. Note the successful true lumen expansion. (Panel D) Axial CT image at 6 months demonstrating excellent perfusion of the visceral arteries and reduced false lumen perfusion.

encouraging early results in patients with complicated Type B dissection and distal bare stent placement after thoracic endovascular aortic repair entry tear coverage. In theory, it may be reasonable to extend this pathologic consequence to patients undergoing hybrid arch surgery for ATAAD and proceed to immediate or staged descending bare metal stenting after hybrid arch repair. Caution, however, is warranted, as there is no clear evidence to support this possibility in this particular clinical setting. As such, we are proposing a multi-center randomized trial to evaluate this potential paradigm shift in the clinical management of ATAAD.

\section{Conflict of Interest}

The authors have no conflict of interest relevant to this publication.

Comment on this Article or Ask a Question

\section{References}

1. Pape LA, Awais M, Woznicki EM, Suzuki T, Trimarchi S, Evangelista A, et al. Presentation, diagnosis, and outcomes of acute aortic dissection: 17-year trends from the international registry of acute aortic dissection. J Am Coll Cardiol. 2015; 66:350-358. DOI: $10.1016 /$ j.jacc. 2015.05.029

2. Czerny M, Schoenhoff F, Etz C, Englberger L, Khaladj N, Zierer A, et al. The impact of pre operative malperfusion on outcome in acute type $A$ aortic dissection: results from the GERAADA registry. J Am Coll Cardiol. 2015;65:2628-2635. DOI: 10.1016/j. jacc.2015.04.030 
3. Tsai TT, Evangelista A. Nienaber CA, Myrmel T, Meinhardt G, Cooper JV, et al. Partial thrombosis of the false lumen in patients with acute type B aortic dissection. New Engl J Med. 2007;357:349-359. DOI: 10.1056/NEJMoa063232

4. Erbel R, Aboyans V, Boileau C, Bossone E, Di Bartolomeo R, Eggebrecht $H$, et al. 2014 ESC Guidelines on the diagnosis and treatment of aortic diseases: document covering acute and chronic aortic diseases of the thoracic and abdominal aorta of the adult. The Task Force for the Diagnosis and Treatment of Aortic Diseases of the European Society of Cardiology (ESC). Eur Heart J. 2014;35:2873-2926. DOI: 10.1093/ eurheartj/ehu281

5. Appoo JJ, Bozinovski J, Chu MW, ElHamamsy I, Forbes TL, Moon M, et al. Canadian Cardiovascular Society/ Canadian Society of Cardiac Surgeons/ Canadian Society for Vascular Surgery joint position statement on open and endovascular surgery for thoracic aortic disease. Can J Cardiol. 2016;32:703-713. DOI: 10.1016/j.cjca.2015.12.037

6. Smith $H$, Boodhwani $M$, Ouzounian $M$, Saczkowski R, Gregory A, Herget EJ, et al. Classification and outcomes of extended arch repair for acute Type A aortic dissection: a systematic review and meta-analysis. Interact Cardiovasc Thorac Surg. 2017;24:450-459. DOI: 10.1093/icvts/ ivw355

7. Tsagakis K, Pacini D, Di Bartolomeo R, Benedik J, Cerny S, Gorlitzer M, et al. Arch replacement and downstream stent grafting in complex aortic dissection: first results of an international registry. Eur J Cardiothorac Surg. 2011;39:87-93. DOI: 10.1016/j.ejcts.2010.03.070

8. Baraki H, Hagl C, Khaladj N, Kallenbach K, Weidemann J, Haverich A, et al. The frozen elephant trunk technique for treatment of thoracic aortic aneurysms. Ann Thorac Surg. 2007;83:S819-S823. DOI: 10.1016/j. athoracsur.2006.10.083

9. Pochettino A, Brinkman WT, Moeller P, Szeto WY, Moser W, Cornelius K, et al. Antegrade thoracic stent grafting during repair of acute DeBakey I dissection prevents development of thoracoabdominal aortic aneurysms. Ann Thorac Surg. 2009;88:482-490. DOI: 10.1016/j.athoracsur.2009.04.046

10. Juvonen T, Ergin MA, Galla JD, Lansman
$\mathrm{SL}$, Nguyen $\mathrm{KH}, \mathrm{McCullough} \mathrm{JN}$, et al. Prospective study of the natural history of thoracic aortic aneurysms. Ann Thorac Surg. 1997;63:1533-1545. DOI: 10.1016/ S0003-4975(97)00414-1

11. Omura A, Miyahara S, Yamanaka K, Sakamoto T, Matsumori M, Okada K, et al. Early and late outcomes of repaired acute DeBakey type I aortic dissection after graft replacement. J Thorac Cardiovasc Surg. 2016;151:341-348. DOI: 10.1016/j. jtcvs.2015.03.068

12. Ullery BW, Wang GJ, Low D, Cheung AT. Neurological complications of thoracic endovascular aortic repair. Semin Cardiothorac Vasc Anesth. 2011;15:123-140. DOI: $10.1177 / 1089253211424224$

13. Ito $N$, Tsunoda T, Nakamura M, lijima R, Matsuda K, Suzuki T, et al. Percutaneous bare Z-stent implantation as an alternative to surgery for acute aortic dissection with visceral ischemia. Catheter Cardiovasc Interv. 2003;58:95-100. DOI: 10.1002/ ccd. 10386

14. Mossop PJ, McLachlan CS, Amukotuwa SA, Ik N. Staged endovascular treatment for complicated Type B aortic dissection. Nat Clin Pract Cardiovasc Med. 2005;2:316-321. DOI: $10.1038 /$ ncpcardio0224

15. Nienaber CA, Kische S, Zeller T, Rehders TC, Schneider H, Lorenzen B, et al. Provisional extension to induce complete attachment after stent-graft placement in type B aortic dissection: the PETTICOAT concept. J Endovasc Ther. 2006;13:738-746. DOI: 10.1583/06-1923.1

16. Hofferberth SC, Foley PT, Newcomb AE, Yap KK, Yii MY, Nixon IK, et al. Combined proximal endografting with distal bare-metal stenting for management of aortic dissection. Ann Thorac Surg. 2012;93:95-102. DOI: 10.1016/j. athoracsur.2011.06.106

17. Hofferberth SC, Newcomb AE, Yii MY, Yap KK, Boston RC, Nixon IK, et al. Combined proximal stent grafting plus distal bare metal stenting for management of aortic dissection: superior to standard endovascular repair? J Thorac Cardiovasc Surg. 2012;144:956-962. DOI: 10.1016/j. jtcvs.2012.07.007

18. Hofferberth SC, Nixon IK, Boston RC, McLachlan CS, Mossop PJ. Stent-assisted balloon-induced intimal disruption and relamination in aortic dissection repair: the STABILISE concept. J Thorac Cardiovasc
Surg. 2014;147:1240-1245. DOI: 10.1016/j. jtcvs.2013.03.036

19. Lombardi JV, Cambria RP, Nienaber CA, Chiesa R, Teebken O, Lee A, et al. Prospective multicenter clinical trial (STABLE) on the endovascular treatment of complicated type B aortic dissection using a composite device design. J Vasc Surg. 2012;55:629-640.e2. DOI: 10.1016/j. jvs.2011.10.022

20. Lombardi JV, Cambria RP, Nienaber CA, Chiesa R, Mossop P, Haulon S, et al. Aortic remodeling after endovascular treatment of complicated type B aortic dissection with the use of a composite device design. J Vasc Surg. 2014;59:1544-1554. DOI: 10.1016/j.jvs.2013.12.038

21. Mirakhur A, Appoo JJ, Kent W, Herget EJ, Wong JK. Delayed intimal blowout after endovascular repair of aortic dissection. J Vasc Interv Radiol. 2013;24:1471-1475. DOI: 10.1016/j.jvir.2013.05.066

22. Weng S-H, Weng C-F, Chen W-Y, Huang C-Y, Chen I-M, Chen C- $\mathrm{K}$, et al. Reintervention for distal stent graft-induced new entry after endovascular repair with a stainless steel-based device in aortic dissection. J Vasc Surg. 2013;57:64-71. DOI: 10.1016/j. jvs.2012.07.006

23. Bertoglio L, Melissano G, Civilini E, Chiesa R. Stent misalignment of the Zenith Dissection Endovascular System. J Vasc Surg. 2013;57:515-517. DOI: 10.1016/j. jvs.2012.07.004

24. Hofferberth SC, Newcomb AE, Yii MY, Yap KK, Boston RC, Nixon IK, et al. Hybrid proximal surgery plus adjunctive retrograde endovascular repair in acute DeBakey type I dissection: superior outcomes to conventional surgical repair. J Thorac Cardiovasc Surg. 2013;145:349-354. DOI: 10.1016/j. jtcvs.2012.07.032

Cite this article as: Kotha VK, Pozeg Zl, Herget EJ, Moon MC, Appoo JJ. Early Results of the PETTICOAT Technique for the Management of Acute Type A Aortic Dissection. AORTA (Stamford). 2017;5(4):124-128. DOI: https://doi.org/10.12945/j.aorta.2017. 17.047 